\title{
Retratos do Programa Saúde da Família em Construções Discursivas de Usuários
}

Pictures Of The Family Health Program in Discourse Constructions Of Its Users

Retratos Del Programa Salud De La Familia En Construcciones Discursivas De Usuarios

Pedro de Oliveira Filho, Thelma Maria Grisi Velôso, Ismaela Macedo Coelho, Audizélia dos Santos Araújo \& Isaac Alencar Pinto

Universidade Estadual da Paraíba
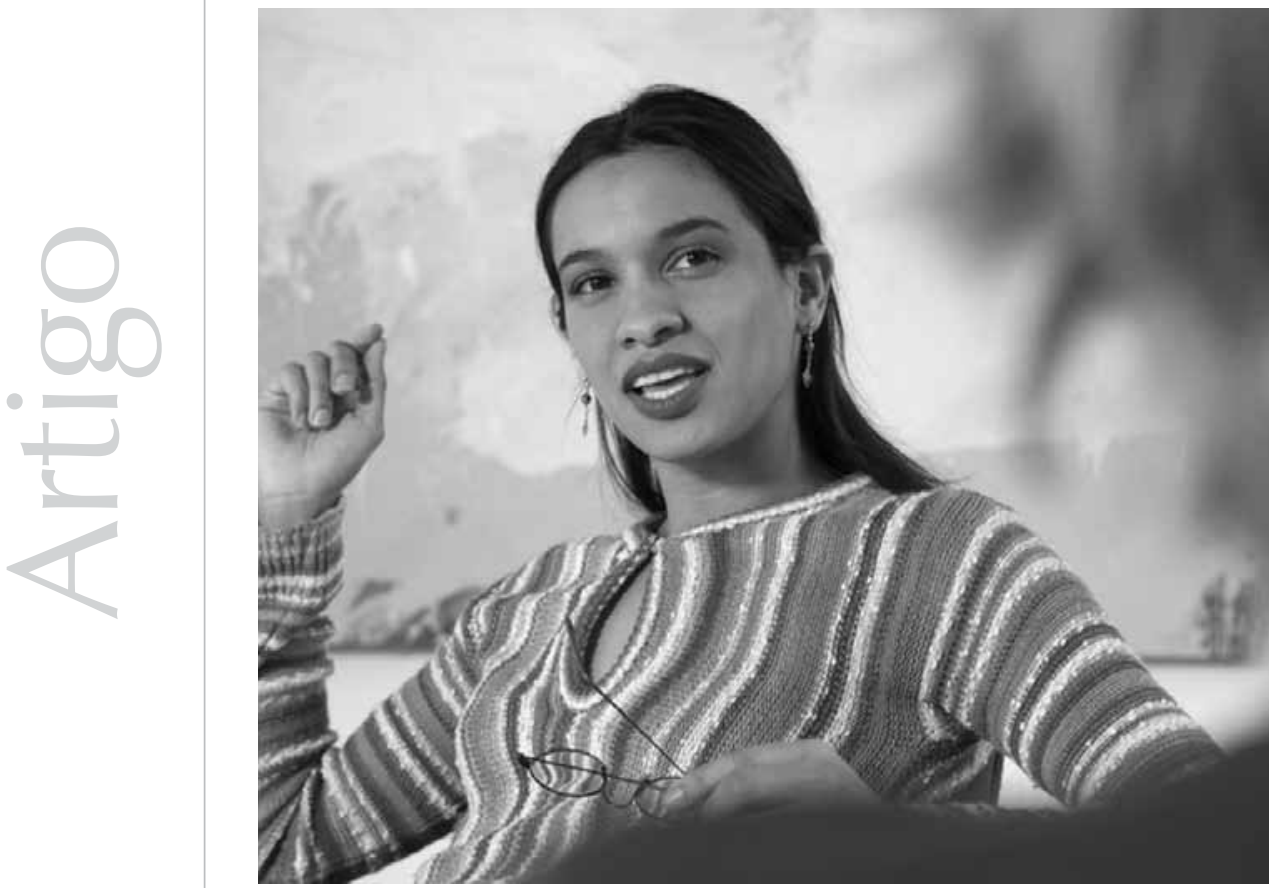
Resumo: Neste trabalho, analisa-se a construção discursiva do Programa Saúde da Família (PSF), de seus profissionais e usuários, em relatos de usuários dos bairros do Pedregal e do Catolé (Campina Grande/ PB). Foram obtidos 16 depoimentos orais de usuários do programa, que foram submetidos ao método de análise de discurso desenvolvido pelos teóricos da Psicologia social discursiva. Nessa abordagem teóricometodológica, de orientação construcionista, privilegia-se, em termos analíticos, a função do discurso (ou seja, suas ações e seus efeitos) e as estratégias retóricas utilizadas em seu uso. Os relatos analisados constroem duas imagens contraditórias do PSF. Em alguns depoimentos, ele aparece como satisfatório e superior ao modelo anterior. Em outros, às vezes em um tom negativo, ele é retratado como ineficaz e pior do que o modelo anterior. Os profissionais do PSF são descritos, em cada um dos depoimentos, com termos e expressões muito semelhantes àqueles usados para descrever o programa. Já os usuários são apresentados, nesses relatos, como pessoas pobres, humildes, sofredoras, sem condições de pagar por um serviço particular. Esses discursos nos remetem à complexidade e aos desafios enfrentados no processo de implementação e efetivação das políticas públicas em nosso país.

Palavras-chave: Políticas públicas. Programa Saúde da Família. Serviços de saúde pública. Atenção primária a saúde. Satisfação do consumidor.

Abstract: In this paper the discourse construction of PSF (Family Health Program) professionals and users
is analyzed as it appears in the reports of users from the districts of Pedregal and Catolé in Campina
Grande, Paraíba. Sixteen oral reports from users of the program were gathered and they were submitted
to the method of discourse analysis developed by theoreticians of social discourse psychology. In analytical
terms, according to this theoretical-methodological approach of constructivist orientation, the function of
discourse (its actions and effects) and the rhetorical devices used are emphasized. The reports under analysis
construct two contradicting images of PSF. In some of these reports it appears satisfactorily and better than
the model previously used. In some others, sometimes, a negative hint can be detected and it is portrayed
as ineffective and worse than the previous one. The PSF professionals are described, in each of the reports,
in terms and expressions similar to those used to describe the program itself. The users, in their turn, are
identified in these reports as poor, humble, suffering people who cannot afford a private health plan. This
discourse reveals the complexity of the challenges to be faced throughout the process of implementation
and execution of public policies in our country. Keywords: Public policies. Users of the Family Health Service. Public health services. Primary health care. Consumer satisfaction.

Resumen: En este trabajo, se analiza la construcción discursiva del Programa Salud de la Familia (PSF), de sus profesionales y usuarios, en relatos de usuarios de los barrios del Pedregal y del Catolé (Campina Grande/PB). Fueron obtenidas 16 declaraciones orales de usuarios del programa, que fueron sometidos al método de análisis de discurso desarrollado por los teóricos de la Psicologia social discursiva. En ese abordaje teórico-metodológica, de orientación construcionista, se privilegia, en términos analíticos, la función del discurso (o sea, sus acciones y sus efectos) y las estrategias retóricas utilizadas en su uso. Los relatos analizados construyen dos imágenes contradictorias del PSF. En algunas declaraciones, aparece como satisfactorio y superior al modelo anterior. En otros, a veces en un tono negativo, es retratado como ineficaz y peor que el modelo anterior. Los profesionales del PSF son descritos, en cada una de las declaraciones, con términos y expresiones muy semejantes a aquellos usados para describir el programa. Ya los usuarios son presentados, en esos relatos, como personas pobres, humildes, sufridoras, sin condiciones de pagar por un servicio particular. Esos discursos nos remiten a la complejidad y a los desafíos enfrentados en el proceso de implementación y efectivación de las políticas públicas en nuestro país.

Palabras clave: Políticas públicas. Programa Salud de la Familia. Servicios de la salud pública. Atención primaria de salud. Satisfación de los consumidores.

Quando pensamos nos anos 70 no Brasil, os associamos rapidamente ao empobrecimento do nosso povo (com o fim do chamado milagre brasileiro) e à implacável repressão política da ditadura militar. Mas é nesse período de franco autoritarismo que diferentes instituições e movimentos sociais começam a levantar a voz por um Brasil mais democrático (Doimo, 1995). E é nesse período, não por acaso, que a luta pela democratização da saúde, encabeçada pelo Movimento da Reforma Sanitária, passa a mobilizar diferentes atores sociais com uma intensidade nunca vista antes (Lucas, 2004).

O propósito principal das discussões, no interior desse movimento, era viabilizar o 
acesso da população à saúde. Todo esse debate teve um papel fundamental na formulação do texto constitucional de 1988, que possibilitou a implantação do Sistema Único de Saúde (SUS) ao partir do princípio de que a atenção à saúde é um direito básico (Lucas, 2004).

De acordo com suas bases técnicas e jurídicas, o SUS representa uma nova formulação política de caráter público, formada por uma rede de serviços regionalizada, hierarquizada e descentralizada, com direção única em cada esfera do Governo e sob o controle dos seus usuários (Brasil, 2004).

Nos anos 90, a participação da comunidade e da família na reorganização dos serviços de saúde passa a ser enfatizada por diferentes setores da sociedade. O programa Agente Comunitário de Saúde (PACS), implantado em 1991, e o Programa Saúde da Família (PSF), implantado em 1994, tornam-se, então, as principais estratégias de reforma do sistema de saúde (Ronzani \& Stralen, 2003).

O PSF, em termos ideológicos, situa-se em um dos lados de uma polarização que confronta duas propostas nas ciências da saúde. De um lado, temos a proposta que enfatiza a especialização e posiciona o hospital como um lugar privilegiado de exercício das práticas profissionais. De outro, temos a proposta fundamentada na estratégia de Atenção Primária à Saúde, que trabalha com o conceito de promoção da saúde, e não somente com o de prevenção, com a ideia de formação generalista para os profissionais de saúde, e com o entendimento de que as práticas de saúde não devem limitar-se à doença em si, mas devem levar em conta o contexto sociocultural onde ela se manifesta. No Brasil, o PSF apresenta-se como uma estratégia alinhada a essa última proposta, visando a implantar um modelo de atenção à saúde da família em todos os seus aspectos (Ronzani \& Stralen, 2003).
Implantado no Brasil pelo Ministério da Saúde, o PSF inspirou-se nas experiências vivenciadas em outros países, como Cuba, Inglaterra e Canadá, e teve como principal objetivo reorganizar, em novos parâmetros, a atenção primária à saúde (Traverso-Yépez, Morais, \& Cela, 2009). Esse programa visa a organizar e a consolidar o SUS, municipalizando a saúde e privilegiando as áreas de maior risco social, e fundamenta-se em uma atenção voltada para a promoção da qualidade de vida, garantindo a integração entre as ações individuais e coletivas no campo da saúde. Nesse novo modelo de saúde, as intervenções não são direcionadas apenas ao indivíduo. A família, na verdade, torna-se o foco das atenções dos profissionais (Ronzani \& Stralen, 2003).

Nesse sentido, a Estratégia Saúde da Família está voltada para “(...) as ações de prevenção, promoção e recuperação da saúde das pessoas, de forma integral e contínua, por meio de atendimentos prestados na unidade básica de saúde, no domicílio ou através da mobilização da comunidade" (Traverso-Yépez et al., 2009, p. 366).

O programa orienta-se pelos princípios de atenção básica, quais sejam: integralidade, qualidade, equidade e participação social. O princípio da integralidade, nesse contexto, refere-se à necessidade de integrar a assistência curativa, a prevenção e a promoção da saúde; o princípio da qualidade evoca uma política de saúde que produz efeitos sobre a saúde global das pessoas e populações; o princípio da equidade procura garantir a promoção da saúde, a saúde curativa e a saúde preventiva para todos os grupos e setores da sociedade; já o princípio de participação social referese à influência dos usuários na gestão dos serviços e das políticas de saúde (Ronzani \& Stralen, 2003).

Propõe-se que os profissionais do PSF (agentes comunitários de saúde, auxiliares de enfermagem, assistentes de odontologia, 
enfermeiras, médicos e odontólogos) trabalhem em equipe, valorizando a interdisciplinaridade e atuando em territórios delimitados.

Na cidade de Campina Grande/PB, o PSF foi implantado em maio de 1994. Naquele ano, o Ministério da Saúde constituiu uma coordenação nacional do Programa Saúde da Família, cuja finalidade era selecionar Municípios que seriam pioneiros na implementação dessa proposta, tendo por base as experiências de Cuba e de Niterói/ RJ com o Programa Médico da Família (Mendonça \& Sousa, 2004).

As condições socioeconômicas e sanitárias desfavoráveis e a carência de acesso aos serviços de saúde foram critérios essenciais para definir os bairros onde seria implantado o PSF. Os bairros selecionados inicialmente para a implantação do programa foram: o Pedregal (com três equipes) e o Mutirão do Serrotão (com duas equipes). Atualmente, existem, em Campina Grande, 67 Unidades do PSF distribuídas nas áreas urbana e rural. ${ }^{1}$

Em conversas informais com usuários do PSF, alguns dos autores deste trabalho identificaram expressões de insatisfação quanto ao seu funcionamento. Esse fato motivou uma discussão no nosso grupo de pesquisa sobre os possíveis significados do PSF para a população. A literatura que aborda o PSF, a partir da perspectiva do usuário, indica que as imagens do PSF construídas nos diferentes contextos são contraditórias. Alguns estudos encontram avaliações predominantemente negativas (Trad, Bastos, Santana, \& Nunes 2002; Ramos \& Lima, 2003); outros (Oliveira \& Borges,

1 Informação obtida na Secretária de Saúde do Município de Campina Grande fevereiro 2011. 2008; Shimizu \& Rosales, 2008) relatam avaliações predominantemente positivas.

Partindo desses relatos e dos existentes na literatura sobre as insatisfações com o funcionamento do PSF nos Municípios brasileiros, resolvemos realizar um estudo na cidade de Campina Grande, com o objetivo de compreender o significado do PSF para usuários do programa nessa cidade. Algumas questões de pesquisa orientaram o estudo. Que repertórios interpretativos (termos, metáforas) os usuários de Campina Grande mobilizam para falar do PSF e de seus funcionários? Que argumentos utilizam para apoiar ou combater o modo como o programa em questão funciona em suas comunidades? Como os usuários do PSF são definidos nesses discursos? Em outras palavras, que atributos mobilizam na construção discursiva da identidade do usuário do PSF?

\section{Método}

\section{Participantes}

A partir do critério de tempo de implantação das unidades na cidade de Campina Grande, foram escolhidos para a realização da pesquisa os seguintes bairros: Pedregal, onde foi implantada a primeira equipe do PSF, em 1994, e o Bairro do Catolé, onde o PSF foi implantado em 2003. O objetivo era detectar diferenças entre as produções discursivas coletadas nos dois bairros, com base no pressuposto de que o tempo de implantação desses serviços poderia produzir diferenças no modo como são representados discursivamente.

Participaram da pesquisa 16 usuários - 8, do Bairro do Catolé, e 8, do Bairro do Pedregal, dos quais 5 são homens ( 3 usuários da unidade do Catolé e 2 da unidade do Pedregal) e 11 mulheres (5 usuárias da unidade do Catolé e 6 da unidade do Pedregal). A idade dos entrevistados compreendeu a faixa etária entre 21 e 70 anos. O número total de entrevistas foi definido pelo critério de ponto de saturação, que define o encerramento da coleta quando começa a haver a repetição dos conteúdos (Lang, Campos, \& Demartini, 
(...) "O

depoimento não tem o sentido do estabelecimento da verdade, mas o conhecimento de uma versão" (Lang et al., 2001, p. 12).
2001). A idade mínima de 21 anos foi definida previamente, mas algumas características sociais da amostra, como o predomínio do gênero feminino, por exemplo, deveram-se exclusivamente à acessibilidade. Isso explica porque a amostra é composta principalmente pelas mulheres dos dois bairros. Essas, em sua maioria donas de casa, eram encontradas com mais facilidade nos bairros nos horários em que as entrevistadoras estavam em campo.

\section{Instrumento e procedimentos}

Com o propósito de responder às nossas questões de pesquisa, recorremos, no processo de geração de material discursivo, à metodologia da história oral, através da utilização do depoimento oral, por meio do qual se procura (...) obter dados informativos e factuais, assim como o testemunho do entrevistado sobre sua vivência ou participação em determinadas situações ou instituições que se quer estudar. (...) "O depoimento não tem o sentido do estabelecimento da verdade, mas o conhecimento de uma versão" (Lang et al., 2001, p.12).

No que se refere à realização das entrevistas, solicitamos aos usuários que dessem um depoimento sobre os serviços oferecidos pelo Programa de Saúde da Família referente à equipe do seu bairro. Após esclarecimentos sobre o propósito e os recursos que seriam utilizados, os entrevistados escolheram o local para a realização das entrevistas, que foram todas obtidas em suas residências. No decorrer das entrevistas, os participantes falaram, espontaneamente ou motivados pelo entrevistador, sobre diversos temas: o PSF, o atendimento nas suas unidades e a relação com os profissionais e os usuários, dentre outros. Cabe assinalar que o projeto de pesquisa foi submetido à apreciação do Comitê de Ética e Pesquisa da Universidade Estadual da Paraíba (UEPB). Sendo assim, os depoimentos foram gravados em fita cassete, de acordo com a autorização do entrevistado. Para garantir o anonimato dos participantes, recorremos à utilização de pseudônimos.

\section{Análise}

No processo de análise das entrevistas, amparamo-nos na orientação teóricometodológica da Psicologia social discursiva, representada por um conjunto de psicólogos sociais ingleses (Potter \& Wetherell, 1987; Potter, Wetherell, Gill, \& Edwards, 1990; Wetherell \& Potter, 1992; Potter, 1998; Billig, $1987,1991)$ que enfatizam a importância da linguagem na compreensão dos processos psicossociais.

A Psicologia social discursiva, ou Psicologia discursiva, é a aplicação das ideias da análise de discurso a questões de interesse da Psicologia, análise de discurso entendida como a investigação sobre o uso de falas e textos para realizar determinadas ações (Potter, 2003). O conceito de construção é um dos pilares dessa perspectiva. Nessa perspectiva, segundo Potter et al. (1990), o termo construção tem três sentidos. Em primeiro lugar, procura destacar o caráter manufaturado dos nossos discursos, ou seja, que eles são produzidos a partir de recursos linguísticos já existentes na sociedade. $\mathrm{O}$ termo também é usado para destacar nossas descrições de objetos ou eventos que, necessariamente, envolvem escolha. Como o mundo não nos diz como devemos descrevêlo, e como há uma grande variedade de recursos linguísticos à disposição dos sujeitos, um mesmo fenômeno pode ser descrito de diferentes maneiras. Um terceiro sentido diz respeito ao fato de que, na maior parte do tempo, acessamos o mundo por meio de construções discursivas. 
Apoiados epistemologicamente no construcionismo, os teóricos dessa abordagem entendem o discurso como uma forma de ação social que reproduz continuamente o mundo em que vivemos na medida em que causa efeitos de realismo, apresentando como factual aquilo que descreve, pois gera efeitos concretos na vida social ao produzir e reproduzir grupos sociais, identidades, instituições, etc. Enfim, tratase de uma abordagem que se caracteriza por um especial interesse pelo modo como organizamos o discurso para tornar determinadas versões da realidade factuais, verdadeiras (Potter \& Wetherell, 1992).

Sob a orientação dessa abordagem, este estudo, por exemplo, dispensa uma especial atenção ao conteúdo das descrições do PSF (descrições essas que nos informam sobre os repertórios interpretativos que os usuários dispõem para dar sentido às suas relações com essa instituição) e aos recursos utilizados para tornar essas descrições factuais, verdadeiras, reais; também analisa atentamente o modo como mobilizam enunciados, termos e metáforas para produzir uma identidade para si próprios.

\section{A construção discursiva do PSF e de seus profissionais}

Não detectamos diferenças relevantes em termos de satisfação com o programa entre os usuários da unidade do Pedregal e os usuários da unidade do Catolé. Essa ausência de diferença nos foi sugerida pela análise qualitativa das entrevistas, e não por uma análise estatística (com amostras tão pequenas da população dos dois bairros, torna-se inviável apontar ausência de diferenças, ou diferenças, estatisticamente significativas).

No que diz respeito ao discurso dos usuários dos dois bairros como um todo, pode-se afirmar que, de um modo geral, esse discurso constrói dois tipos de imagens do PSF, que se contradizem. Por um lado, são construídas imagens do programa em que ele aparece como satisfatório, e, de um modo geral, superior ao que existia anteriormente. Por outro lado, ele é retratado como ineficaz e pior do que o modelo anterior. Se fôssemos colocar esses dois posicionamentos em um contínuo, veríamos, claramente, que os relatos que constroem imagens negativas do programa apresentam-se mais enfáticos em sua apreciação negativa. De forma geral, esses discursos são menos ambíguos do que aqueles em que o PSF é posicionado como um programa que atende de maneira satisfatória às necessidades da população.

Esses últimos são marcados, frequentemente, pela ambiguidade, pela dissonância. Poucas falas apresentam apreciações positivas que poderiam ser consideradas monolíticas, como a que podemos ver a seguir.

Eu tô achando muito bom, é muito bom o serviço daqui, porque todo mundo aqui é atendido direito, não tem burocracia... É isso aí, muito médico, médico bom aí, enfermeiro excelente... Tô muito bem lá, muito bem atendido lá... (...) É uma equipe que trabalha muito bem, vem nas casas direitinho, as agentes de saúde vêm nas casas, supervisora... Vêm, vêm examinar se tem alguém doente. Trata muito bem mesmo, os agentes de saúde (João, 50 anos, usuário do Pedregal).

Na fala de João, nenhuma deficiência ou fragilidade é apontada em relação ao atendimento dos profissionais do PSF. O uso recorrente da expressão muito bem constrói um tipo de relação entre o PSF e os seus usuários marcada pela ausência de tensão. O modelo hospitalocêntrico é tacitamente citado, quando João se refere à ausência de burocracia no PSF e cita as visitas das agentes de saúde às residências dos usuários.

Em outras falas, em que o PSF também é 
retratado de maneira positiva, podemos perceber notas dissonantes, como estas:

\begin{abstract}
Melhorou... Porque antes a gente tinha que sair muito cedo pra aquele posto (pausa) que fica em frente à rodoviária, aí se não saísse cedo não pegava a ficha; também tinha dia que a pessoa dava viagem perdida, ou quando era no tempo do barracão (atual Hospital Universitário), o povo saia cedo pra lá, pra ir pra lá, tinha que madrugar. Numa parte eu gostei, sabe? Pelo menos facilitou um bocado de coisas (...) Os serviços, na parte de médico, ela é boa, agora o que falta muito é medicação (...) Mas o problema é que se... falta, os pobres às vezes não tem como comprar medicação, aí falta! E o resultado dos exames que é demorado demais, também! (Amélia, 50 anos, usuária do Catolé).
\end{abstract}

Sobre o PSF, olha... a gente só tem a agradecer, porque colocaram esse posto de atendimento, antes a gente tinha que se deslocar até o HU (Hospital Universitário), né, que é muito longe, agora não... Tá perto (...) É ótimo (enfático). O atendimento é muito bom! Os médicos são bons, primeiro aí a gente não tem do que se queixar, é bom (enfático), o atend... é excelente, eu mesmo gosto! (...) Tem o enfermeiro... (diz o nome), ele é muito bom! O que a gente precisa sempre tem, entendeu? (...) Eles atendem bem... Atendem bem, a gente não se queixa porque toda vez que a gente precisa, eles estão ali, em todo canto tem que esperar, né? É claro que ninguém pode ser atendido na hora que chega, mas... Eles atendem bem... Atendem bem todo mundo... Tendo paciência, dá pra esperar que... Eles atendem direitinho (Lenilce, 52 anos, usuária do Catolé).

O discurso de Amélia compara o PSF ao modelo de atendimento que existia antes, modelo da ficha, que obrigava as pessoas a madrugar para serem atendidas, um modelo que implicava o deslocamento das pessoas, a perda de tempo, e o PSF é claramente retratado como mais satisfatório. Mas, aqui, são mencionadas características negativas do programa. Segundo ela, "falta medicação", e os resultados dos exames são demorados.
A questão da medicação, como alertam Traverso-Yépez et al.(2009), ainda está muito enraizada na mentalidade da população, que reproduz uma visão do modelo biomédico e de uma perspectiva curativa. Isso pode estar sinalizando a dificuldade dos usuários de compreenderem e aceitarem a proposta do PSF pelo fato de terem ainda expectativas ligadas ao modelo anterior; por outro lado, também sinaliza a falta de um diálogo e de reflexão dos profissionais com a comunidade a respeito da nova proposta.

No discurso de Lenilce, a proximidade das unidades do programa em relação às residências e a qualidade do atendimento prestado pelos profissionais constituem também aspectos relevantes na sua descrição do PSF, que contrasta com o atual modelo de atendimento hospitalocêntrico, quando ressalta essa proximidade. No que diz respeito ao atendimento, há certa ambiguidade no discurso de Lenilce. A princípio, ela qualifica o PSF de "excelente", "bom", em um discurso extremamente elogioso. No final de seu relato, ela aponta a demora no atendimento, mas o faz tentando justificar o problema, de tal maneira que a demora aparece quase como um fato natural, universal, e não como um problema social, contingente: - Em todo canto tem que esperar, né? É claro que ninguém pode ser atendido na hora que chega. No final de sua fala, o tom extremamente elogioso que usava termos como "excelente", "bom" transformase em um tom mais moderado, modesto, materializado no diminutivo "direitinho".

Como dissemos anteriormente, os discursos que constroem imagens negativas do programa são mais enfáticos. Comparados com os discursos em que predomina uma apreciação positiva do programa, como os analisados anteriormente, esses discursos são mais assertivos, monolíticos. 
(...) Eu tenho problemas de saúde, mas quando eu preciso (pausa), eu pago os exames. Há poucos dias mesmo, semana passada, eu fiz, eu paguei, na clínica particular lá, é, mas barata, perto da CLIPSI (Clinica e Pronto Socorro Infantil). (...) Não gosto. Achei que as coisas pioraram muito depois dele (PSF), que antes a gente ia direto para o hospital, né? Agora, quando a gente chega lá, tem que ser enviado, encaminhado, pelo posto do bairro (Teresa, 65 anos, usuária do Catolé).

E... (pausa) mau atendimento, porque a gente chega não tem médico (pausa), e tem pessoas que não sabem atender, não posso citar o nome porque eu não conheço, né? Graças a Deus, só precisei uma vez, mas nessa mesma vez que eu precisei, foi péssimo (enfático) o atendimento (...) A médica disse que não... pode levar pra casa, que isso é gripe, que muitas vezes é uma gripe mal curada, né? Só que não era... era um...um...problema mais sério, o menino ficou internado e eu fui pela conversa da médica e o menino morrendo em casa... morrendo em casa (...) (Fátima, 42 anos, usuária do Pedregal).

O posto é assim, sabe, a gente vai, aí chega lá, fica na fila, aí passa um ano para ser atendida, entendeu? Aí a gente chega lá, o médico atende a gente? Não, a menina atende a gente, faz a ficha da gente, aí a gente passa mais de meia hora para ser atendida (pausa); o médico passa o medicamento, não tem, entendeu? Aí a gente vai marcar um exame, passa um ano lá pra marcar, passa dois, dois meses, três meses, entendeu? Quando a gente vai atrás, não está marcado. E eu sei que a gente fica nessa penitência, passa um ano para marcar um exame. Eu... não tá 'com nada no balaio lá, não' (Rosa, 52, anos, usuária do Pedregal).

Teresa posiciona-se como alguém que não tem necessidade de recorrer ao PSF quando tem problemas de saúde, que despreza o programa tal como ele se apresenta no seu bairro. Compara o passado, quando as pessoas eram hospitalizadas, com o presente, no qual "as coisas pioraram muito".
Fátima desqualifica o programa sem rodeios ou meias palavras. No PSF do seu bairro, o atendimento é ruim, faltam médicos, e, quando eles aparecem, não atendem bem. Para tornar mais convincente sua argumentação, narra uma história na qual o filho quase morreu em decorrência do mau atendimento médico: $O$ menino morrendo em casa... morrendo em casa.

O discurso de Rosa é ainda mais contundente do que o de Fátima. Sua descrição do mundo dos usuários do PSF é um mundo no qual se debatem personagens que são jogados de um lugar para outro por burocratas insensíveis e evasivos. O tom hiperbólico presente em algumas passagens ("aí passa um ano para ser atendida") e o uso do termo "penitência", como metáfora para essas situações, produzem um retrato do PSF em que os usuários são cotidianamente enredados em situações absurdas e incompreensíveis. Por fim, desqualifica o programa: Não tá com nada no balaio lá, não.

Quando solicitados a falar especificamente sobre os profissionais do PSF, os usuários, assim como nas descrições do PSF, também não produziram uma imagem única. Como assinalam Davies e Harré (1990 citado por Traverso-Yépez et al., 2009, p. 366), “(...) quando alguém assume um posicionamento, revela na sua estrutura de valores e no uso que faz de determinado repertório tanto um conjunto conceitual/interpretativo quanto uma visão da pessoa de quem se está falando".

Assim, ao falar dos profissionais, os usuários também sinalizam a forma como se relacionam com eles. Aparecem, da mesma forma que em relação ao PSF, apreciações negativas dos profissionais que lá trabalham, no entanto, de forma bem mais enfática e menos marcada pela ambiguidade do que as apreciações positivas. Os três exemplos a seguir são bem 
representativos das apreciações negativas dos profissionais:

Ôxe... várias pessoas desse atendimento novo mesmo é... reclamam porque chegam lá e não tem médico, os enfermeiros são chatos, as auxiliares são chatas, ficam reclamando, sabe? (Fátima, 42 anos, usuária do Pedregal).

É... Os profissionais só fazem o que os chefes quiserem (pausa) somente... (...) Eles mesmos também nem se interessam a fazer isso por esse povo de idade, eles não se interessam pelo serviço (Carlos, 70 anos, usuário do Pedregal).

(...) - Eu não vou pra nada mesmo, entendeu? Lá.

Pesquisador: - Realmente não pisa lá?

- Não. Não, porque acho que o povo, acha assim, o povo meio aborrecido, o povo que atende a umas pessoas e não atende direitinho, não atende a outras, por isso que tem muita gente que gosta, que é bem atendido. Tem gente que chega aqui: - Por que você não vai? Eu fui e fui bem atendido, eu digo: - Bem, você foi, mas eu não fui". (Teresa, 65 anos, usuária do Catolé).

Fátima utiliza o adjetivo chato para caracterizar os profissionais, os enfermeiros e os auxiliares que trabalham na unidade do Pedregal, qualificativo usado para indicar um atendimento insatisfatório. Em relação aos médicos, nenhum qualificativo explícito é utilizado. Afirma simplesmente que "não tem médico", enunciado que, nesse contexto, é uma tentativa de descrever e denunciar, com o tom hiperbólico, um atendimento precário e as constantes ausências do profissional médico.

Carlos prossegue no mesmo tom hiperbólico. O desinteresse pela saúde dos idosos e pelo próprio serviço é a característica definidora dos profissionais em seu relato.
Teresa também relata uma experiência negativa com os profissionais do PSF. Para essa entrevistada, os profissionais são pessoas aborrecidas, que selecionam os atendimentos, uma vez que "atende a umas pessoas e não atende direitinho, não atende outras". Mas, diferentemente de Fátima e de Carlos, apresenta um retrato menos negativo, mais matizado e, por isso mesmo, mais verossímil do atendimento dos profissionais do PSF, um retrato construído, em parte, por vozes contrárias à da própria Tereza, uma das quais aparece no seu relato, contrariando, ao dizer "eu fui e fui bem atendido", a imagem que Tereza está construindo. Essa voz, por sua vez, é contestada por Tereza, quando afirma (supostamente fundamentada na experiência pessoal, assim como a autora da voz citada por ela): Bem, você foi, mas eu não fui.

Como dissemos anteriormente, as apreciações positivas são mais ambíguas do que as apreciações negativas. Com isso, queremos ressaltar que esses relatos são atravessados por termos, expressões e hesitações que desestabilizam o retrato positivo do atendimento dos profissionais que eles tentam produzir. Essas características das apreciações positivas são bem evidentes na fala de Amélia, abaixo:

Olhe! A turma do início que começou... são boas demais, agora tem uma turma nova que faz um mês e pouquinho que começou nesse concurso, eu não posso dizer nada porque... porque não sei os serviços deles, né? (...) Não... Tinha, olhe... O tratamento antes, tinha um enfermeiro que ele não passou nesse concurso, era ótimo demais, acho que não nasce outro melhor do que ele (enfático), o tratamento pra mim mesmo, eu gosto de tudinho, porque trata bem a pessoa (...) Eles atendem bem (pausa) se a pessoa pedir... Que em todo canto a pessoa tem que falar também, né? Falar direito, né? Se for com 'má criação', o cabra não resolve nada também. Mas o restante tá bem! (...) Eu gostaria que trabalhasse com carinho, amor do jeito que eles trabalham... (Amélia, 50 anos, usuária do Catolé). 
Amélia inicia seu relato ressaltando as qualidades da antiga equipe que trabalhava na unidade, e, logo a seguir, afirma que não pode julgar a nova equipe porque nada sabe sobre ela. Antes de fazer essa afirmação, hesita, e, logo em seguida, depois de hesitar novamente, passa a falar sobre as qualidades positivas da antiga equipe, destacando a figura de um enfermeiro, que "era ótimo demais". Logo a seguir, depois de dizer que gosta de todos os profissionais, o seu relato passa a construir uma imagem das relações entre profissionais e usuários marcada por conflitos, tensões: Eles atendem bem (pausa) se a pessoa pedir... Que em todo canto a pessoa tem que falar também, né? Falar direito, né? Se for com 'má criação', o cabra não resolve nada também. É importante observar que um conjunto de ações que poderiam ser caracterizadas como indicadoras de submissão são apresentadas nesse relato como uma estratégia a ser usada pelos usuários para garantir um bom atendimento.

A ambiguidade também caracteriza este relato de Lenilce:

Os médicos são bons, primeiro aí a gente não tem do que se queixar, é bom (enfático). (...) Eles atendem bem... atende bem, a gente não se queixa, porque toda vez que a gente precisa, eles estão ali e a gente espera um pouco, em todo canto tem que esperar, né? (Lenilce, 52 anos, usuária do Catolé).

Segundo Lenilce, os profissionais são pessoas que atendem bem e que estão dispostos a oferecer a sua assistência aos usuários nos momentos de necessidade. Fala do bom atendimento prestado pelos profissionais; no final de seu discurso, no entanto, afirma que os usuários esperam um pouco pelo atendimento e conclui, em um tom de conformismo, dizendo que "em todo canto tem que esperar".
Diante de tais relatos, perguntamos, assim como Traverso-Yépez et al.(2009), se os usuários não teriam uma expectativa assistencial que se choca com a proposta de promoção e de prevenção da saúde adotada pelo programa.

\section{Os usuários do PSF}

Um dos nossos interesses foi também analisar a construção discursiva da identidade dos usuários por eles próprios. Pressupõe-se que as posições identitárias assumidas pelos membros dos diferentes grupos e categorias sociais e os próprios grupos e as categorias sociais são produzidos continuamente no interior de práticas discursivas e classificatórias (Wetherell \& Potter, 1992).

Nas falas analisadas, predomina um repertório que ressalta a pobreza dessas pessoas. Os relatos abaixo são bem representativas desse repertório:

Pessoas que não podem pagar plano de saúde... pessoas que não tem condições de fazer uma consulta particular, pagar dinheiro, mesmo, pessoas que realmente necessitam do SUS. (...) Porque as pessoas são humildes, os pacientes do PSF são humildes, é... eles muitas vezes não sabem ler nem escrever (Gabriela, 24 anos, usuária do Pedregal).

Pesquisador: - E assim, no caso, pra senhora, quem são os outros usuários do PSF?

Entrevistada: (silêncio) - Eu acho que quase todo bairro pobre, né? Que não tem condições de (pausa), de comprar um medicamento, muito embora não tenha medicamento, pelo menos os que eu tomo não tem aí no posto, nunca ouvi falar que tenha (Teresa, 65 anos, usuária do Catolé).

Não, é gente bem humilde, bem baixinho, mesmo... (...) Mas, assim mesmo, é cada qual com... um falando da vida do outro (risos). Tudo contente, né? Os que estão tristes são 
aqueles que estão muito doentes, né? Que não tem alegria, né? (Graça, 50 anos, usuária do Pedregal).

O que eu poderia dizer, os usuários do... do PSF que sofre muito, né? É... são pessoas carentes, que não têm condições de poder... inclusive de procurar outros recursos, né? (Francisco, 54 anos, usuário do Catolé).

As falas supracitadas atribuem aos usuários do PSF uma característica comum: a pobreza. Termos como carentes, humildes, ou expressões como bem baixinho, mesmo são usadas pelos sujeitos para nomear as pessoas pobres que recorrem ao programa. Em nosso meio cultural, essas expressões, que podem ser usadas, e às vezes o são, para falar de características psicológicas ou físicas de pessoas com diferentes níveis de renda, são empregadas para nomear o indivíduo pobre e com pouco poder em nossa sociedade, ou seja, indivíduos sem renda ou com renda muito pequena, sem influência social.

A associação entre pobreza e ausência de poder, por um lado, e características como a humildade, por outro lado, são bem antigas. No século XIX, Nietzsche (1985), em Genealogia da Moral, via a humildade como uma característica atribuída historicamente pelos grupos dominados, particularmente os primeiros cristãos, a si próprios, como uma forma de distinguir-se dos grupos aristocráticos. No século passado, no Brasil, Ianni (1972) observava que características como humildade e submissão eram comumente atribuídas à população negra.

Portanto, ao empregar termos como humilde ou carente para nomear o usuário do PSF, esses sujeitos descrevem esses usuários e, em consequência, a si próprios, com os mesmos traços usados tradicionalmente no Brasil para descrever os grupos dominados.
Como ressaltam Spink e Medrado (1999), os discursos não só descrevem as realidades dos atores sociais mas também moldam essas realidades, à medida que expressam o conteúdo proposicional e, ao mesmo tempo, indicam o ato que desejam efetuar.

É interessante notar, na fala de Graça, a rejeição da ideia de que o sofrimento e a infelicidade seriam atributos próprios dos usuários do PSF, dos sujeitos pobres. Ela usa a partícula de oposição mas para produzir essa dissociação: Não, é gente bem humilde, bem baixinho, mesmo... (...) Mas assim mesmo é cada qual com... um falando da vida do outro (risos), tudo contente, né?" No relato de Francisco, por outro lado, a pobreza é associada à infelicidade: o usuário do PSF "sofre muito", por ser "carente" e não poder "procurar outros recursos.

Outras características são citadas. Afirmar que essas pessoas "não podem pagar plano de saúde", que não podem "fazer uma consulta particular" ou "comprar medicamentos" é atribuir-lhes um conjunto de características consistentes com as outras discutidas anteriormente. Esses usuários são posicionados como aqueles cidadãos que dependem dos serviços públicos de saúde, em contraposição àqueles que podem dispensá-los e pagar por serviços privados.

O discurso dessas pessoas termina por reafirmar o formato que tem sido adotado pelo sistema de saúde no Brasil, um formato pretensamente universalista, mas que, na prática, reserva serviços de saúde estatais para os pobres e empurra os setores médios para os planos privados de saúde.

\section{Considerações finais}

A análise dos discursos dos participantes desta pesquisa apresenta, de maneira 
clara, as tensões que atravessam os atos de significação relacionados ao PSF em duas unidades do programa na cidade de Campina Grande. Deparamo-nos com usuários que ressaltam as qualidades do PSF, como o fato de as residências se localizarem próximo às unidades e o bom atendimento prestado pelos profissionais. Defrontamo-nos também com aqueles que relatam insatisfação com os serviços, sobretudo no que se refere ao mau atendimento dos profissionais, à falta de medicação e à demora no atendimento.

Há que se destacar que os relatos com imagens negativas do programa e de seus funcionários são bem mais enfáticos e menos ambíguos em sua apreciação negativa do que os relatos com apreciações positivas. Quando falam de si próprios, os participantes apresentam-se como pobres, carentes, humildes, como pessoas que não têm condições de ter uma assistência de saúde privada e que precisam recorrer aos serviços públicos de saúde.

A variabilidade detectada nessas falas está, certamente, relacionada à experiência desses sujeitos no interior das unidades do PSF, mas essa não é uma experiência pura e direta, é uma experiência mediatizada por discursos de diferentes origens, que definem, de diferentes maneiras, o posicionamento desejável dos cidadãos brasileiros de diferentes classes sociais em relação aos serviços públicos do Estado.

Esses relatos terminam por indicar os desafios que se colocam frente à implementação das políticas públicas de saúde que buscam, entre outros aspectos, construir uma prática que estimule o protagonismo dos atores sociais envolvidos, para que se tornem sujeitos ativos no processo de produção de saúde. 


\section{Pedro de Oliveira Filho}

Doutor em Psicologia Social pela Pontifícia Universidade Católica de São Paulo. Professor da Unidade Acadêmica de Ciências da Saúde da Universidade Federal de Campina Grande, Paraíba- PB- Brasil, e do Programa de Pós-Graduação em Psicologia da Universidade Federal de Pernambuco, Pernambuco - PE - Brasil. E-mail: deoliveirafilhopedro@gmail.com

\section{Thelma Maria Grisi Velôso}

Doutora em Sociologia pela Universidade Estadual Paulista Júlio de Mesquita Filho. Professora do Departamento de Psicologia da Universidade Estadual da Paraíba, Paraíba - PB - Brasil, e do Programa de Pós-Graduação em Serviço Social da mesma universidade.

E-mail: thelma.veloso@ig.com.br

\section{Audizélia dos Santos Araújo}

Graduada em Psicologia pela Universidade Estadual da Paraíba, Paraíba - PB - Brasil. Coordenadora de Psicologia da Associação de Pais e Amigos dos Excepcionais de Campina Grande, Paraíba - PB - Brasil.

E-mail: audizelia@hotmail.com

\section{Isaac Alencar Pinto}

Mestre em Psicologia pela Universidade Federal de Pernambuco. Professor do Curso de Psicologia da Faculdade de Ciências da Saúde de Serra Talhada, Pernambuco - PE - Brasil.

E-mail: isaacalencar@gmail.com

\section{Endereço para envio de correspondência:}

Unidade Acadêmica de Ciências da Saúde, Universidade Federal de Campina Grande. Rua Aprigio Veloso, 882, Bairro Universitário, Campina Grande- PB- Brasil. CEP: 58429-900.

Recebido 13/5/2011, 1a Reformulação 28/2/2012, Aprovado 16/4/2012. 


\section{Referências}

Billig, M. (1987). Arguing and thinking: A rhetorical approach to social psychology. Cambridge: Cambridge University Press.

Billig, M. (1991). Ideology and opinions. London: Sage Publications.

Brasil. Ministério da Saúde. (2004). VER-SUS Brasil: cadernos de textos. Brasília, DF: Autor.

Doimo, A. M. (1995). A vez e a voz do no popular: movimentos sociais e participação política Brasil pós-70. Rio de Janeiro: ANPOCS/Relume-Dumará.

lanni, O. (1972). Raças e classes sociais no Brasil. Rio de Janeiro: Civilização Brasileira.

Lang, A. B. S. G., Campos, M. C. S. S., \& Dermatini, Z. B. S. (2001). História oral e pesquisa sociológica: a experiência do CERU. São Paulo: Humanitas.

Lucas, A. M. S. (2004). Prazer e sofrimento psíquico nos profissionais de enfermagem do PSF. Dissertação de mestrado. Departamento de Enfermagem, Universidade Estadual da Paraíba, Campina Grande, PB.

Mendonça, A. V. M., \& Sousa, M. F. (2004). Dez anos do PSF em Campina Grande: o sentir e o fazer - suas vozes. Rio de Janeiro: CEBES.

Nietzsche, F. W. (1985). A genealogia da moral. São Paulo: Editora Moraes.

Oliveira, A. K. P., \& Borges, D. F. (2008). Programa de Saúde da Família: uma avaliação de efetividade com base na percepção de usuários. Revista de Administração Pública, 2, 369-389.

Potter, J. (2003). Discourse analysis and discursive psychology. In P.M. Camic, J. E. Rhodes \& L. Yardley (Orgs.), Qualitative research in psychology: Expanding perspectives in methodology and design (pp. 73-94). Washington: American Psychological Association.

Potter, J., \& Wetherell, M. (1987). Discourse and social psychology: Beyond attitudes and behaviour. London: Sage.
Potter, J., Wetherell, M., Gill, M., \& Edwards, D. (1990). Discourse: Noun, verb or social practice? Philosophical Psychology, 3, 205-217.

Potter, J. (1998). La representación de la realidad: Discurso, retórica y construcción social. Barcelona: Paidós.

Ramos, D. D., \& Lima, M. A. D. S. (2003). Acesso e acolhimento aos usuários em uma unidade de saúde pública de Porto Alegre, Rio Grande do Sul, Brasil. Caderno de Saúde Pública, 1, 27-34.

Ronzani, T. M., \& Stralen, C. J. V. (2003). Dificuldades de implantação do Programa de Saúde da Família como estratégia de reforma do sistema de saúde brasileiro. Revista de Atenção Primária, 2, 99-107.

Shimizu, H. E., \& Rosales, C. (2008). Atenção à saúde da família sob a ótica do usuário. Revista Latino-americana de Enfermagem, 5, 883-888.

Spink, M. J., \& Medrado, B. (1999). Produção de sentido no cotidiano: uma abordagem teórico-metodológica para análise das práticas discursivas. In M. J. Spink (Org.), Práticas discursivas e produção de sentidos no cotidiano: aproximações teóricas e metodológicas (pp. 41- 61). São Paulo: Cortez.

Trad, L. A. B., Bastos, A. C. S., Santana, E. M., \& Nunes, M. O. (2002). Estudos etnográficos de satisfação do usuário do PSF na Bahia. Ciência \& Saúde Coletiva, 3, 581-589.

Traverso-Yépez, M., Morais, A. S., \& Cela M. (2009). Construções discursivas acerca do usuário do Programa Saúde da Família (PSF). Psicologia: Ciência e Profissão, 29, 364-379.

Wetherell, M., \& Potter, J. (1992). Mapping the language of racism: Discourse and the legitimation of exploitation. New York: Harvester Wheatsheaf. 